\title{
The Influence of MHC and Immunoglobulins A and E on Host Resistance to Gastrointestinal Nematodes in Sheep
}

\author{
C. Y. Lee, ${ }^{1}$ K. A. Munyard, ${ }^{1}$ K. Gregg, ${ }^{1}$ J. D. Wetherall, ${ }^{1}$ M. J. Stear, ${ }^{2}$ and D. M. Groth ${ }^{1}$ \\ ${ }^{1}$ Curtin Health Innovation Research Institute and Western Australian Biomedical Research Institute, Curtin University, Perth, \\ WA 6845, Australia \\ ${ }^{2}$ Department of Animal Production and Public Health, School of Veterinary Medicine, University of Glasgow, Bearsden Road, \\ Glasgow G61 1QH, UK
}

Correspondence should be addressed to D. M. Groth, d.groth@curtin.edu.au

Received 29 November 2010; Revised 17 February 2011; Accepted 18 February 2011

Academic Editor: Alvin A. Gajadhar

Copyright $\odot 2011$ C. Y. Lee et al. This is an open access article distributed under the Creative Commons Attribution License, which permits unrestricted use, distribution, and reproduction in any medium, provided the original work is properly cited.

Gastrointestinal nematode parasites in farmed animals are of particular importance due to their effects on production. In Australia, it is estimated that the direct and indirect effects of parasite infestation cost the animal production industries hundreds of millions of dollars each year. The main factors considered by immunologists when studying gastrointestinal nematode infections are the effects the host's response has on the parasite, which immunological components are responsible for these effects, genetic factors involved in controlling immunological responses, and the interactions between these forming an interconnecting multilevel relationship. In this paper, we describe the roles of immunoglobulins, in particular IgA and IgE, and the major histocompatibility complex in resistance to gastrointestinal parasites in sheep. We also draw evidence from other animal models to support the involvement of these immune components. Finally, we examine how IgA and IgE exert their influence and how methods may be developed to manage susceptible animals.

\section{Introduction}

Gastrointestinal worm infestation is one of the major causes of reduced productivity in domestic sheep in tropical and temperate regions of the world. In common with other parasitic infections, there is a complex interaction between the host's innate and adaptive defence mechanisms and consequent adaptations by the parasite. An understanding of these interactions is essential for the development of sustainable strategies to minimise the impact of the parasite burden on the host. Analysis of the problem is made more difficult by the diversity of nematode species and strains that commonly infect sheep and the apparently variable manner in which sheep respond to these organisms.

Inherited factors play an important role in determining susceptibility to nematode infections. For example, over the past two decades, the Rylington Merino Project has selected sheep for resistance to nematodes on the basis of annual worm egg counts $[1,2]$. Relative to a control flock, the selected flock now has sufficient inherited resistance to nematodes that anthelminthic chemicals are not required during the lambing season. Selective breeding has been successful in other research flocks [1, 3, 4] and many commercial farms. Resistant animals can be identified by measuring faecal egg counts (FECs) over the first year of life. Selection for nematode resistance is widely practised in Australia and New Zealand but less common in the rest of the world.

In Australia and New Zealand, the correlations between FEC and growth rate have been weak [5-7]. In contrast, in Europe, the correlations are strong [8-10] but have been shown to change over time. The differences may reflect the breed of sheep in the different regions, that is, Australian Merino, New Zealand Romney, Scottish Blackface, and Polish long wool sheep. Alternatively, the differences may be a consequence of the nematode community. In the two European FEC studies, egg counts were predominantly Teladorsagia circumcincta but in the Australian and New Zealand studies, Haemonchus contortus or Trichostrongylus colubriformis made a much greater contribution to egg 
counts. Alternatively, the differences between Europe and Australasia could reflect the different husbandry conditions; European sheep generally reach sale weights at an earlier age. $\operatorname{IgA}$ and IgE responses have been associated with reduced egg counts, but IgE responses have been shown to develop more slowly and are associated with pathology [11].

Many studies have implicated variation within the major histocompatibility complex (MHC) as a determinant of host resistance and/or sensitivity to gastrointestinal parasitism in several species [12]. In addition, mucosal humoral responses to parasites have been implicated in mechanisms that restrict parasite growth and mediate the expulsion of worms [13]. In this paper, the roles of the MHC and immunoglobulin synthesis, especially IgA and IgE, are discussed with particular emphasis on nematode infections in sheep.

\section{Role of Adaptive Immunity in Gastrointestinal Parasitic Infestation}

Parasitic gastroenteritis is caused by nematodes that include species from the genera Trichostrongylus, Teladorsagia, Haemonchus, Nematodirusi, and Cooperia [14]. Infections usually arise from ingestion of parasite larvae or eggs from pasture, and it is well established that the presence of parasite antigens in the host's gastrointestinal system triggers innate immune responses, in addition to humoral and cell-mediated adaptive responses, with recruitment of $\mathrm{T}$ cells along the gastrointestinal mucosa $[15,16]$. During an initial infection, dendritic cells take up and process parasite molecules. The dendritic cells then migrate to the draining lymph nodes and activate $\mathrm{T}$ cells, although additional interactions between antigen presenting cells and $\mathrm{T}$ cells may occur close to the site of uptake. In the small intestine, soluble antigens (metabolic or excretory-secretory components) are absorbed by specialised microfold cells in the follicle-associated epithelium overlying the Peyer's patches either through phagocytosis or pinocytosis [17]. Antigens are transported from the intestinal lumen to the subepithelial dome, where the antigen-presenting cells interact with $\mathrm{T}$ cells.

The importance of $\mathrm{T}$ lymphocytes, which regulate the host adaptive response against gastrointestinal parasites, has been demonstrated in several laboratory animal models, including Trichinella spiralis, Heligmosomoides bakeri, and Strongyloides stercoralis $[12,37,38]$ and also in sheep infected with Haemonchus contortus [39]. However, it is also clear that adaptive immune responses to nematode parasites do not completely prevent subsequent infection, at least in most animals within a flock.

The three major manifestations of resistance to nematodes are reduced numbers of adult nematodes, decreased size of adult nematodes, and increased numbers of inhibited larvae, compared to susceptible contemporaries. However, not all resistant animals manifest all the three primary indicators, and the three indicators do not develop at the same rate $[40,41]$. Large worms tend to lay more eggs [42] and are generally more pathogenic [11]. Reduced egg counts, increased expulsion of parasites, altered growth rates in resistant hosts, increased numbers of eosinophils, mast cells, plasma cells, and lymphocytes as well as increased concentrations of antibody are common secondary indicators in most nematode infections of sheep.

Much of the current knowledge concerning the mammalian immune response to parasites comes from studies on laboratory animals, particularly rodents. Experimental infections in rodents have provided valuable information for the analysis of immunological and genetic mechanisms that determine resistance to gastrointestinal nematode parasites $[32,43]$. The demonstration that genetic factors influence resistance and susceptibility in mice allows the identification of genetic markers or genes that confer resistance [43]. Although the genes controlling resistance in different species are unlikely to be identical, many of the pathways are likely to be similar.

\section{The Role of IgA in Nematode Resistance}

In several host-parasite systems, parasite-specific IgA has been associated with resistance [44-48]. However, careful experimental design and interpretation are needed because IgA responses to nematode infection are correlated with IgE production, together with infiltration of eosinophils and mast cells and the subsequent degranulation of mast cells [49]. The mutual correlations could be a consequence of cytokines from Th2 cells, which recruit the relevant cells. Therefore, it is possible that increased IgA activity may be a marker of an increased mucosal immune response. IgA is not complement fixing and recently has been implicated in anti-inflammatory mechanisms [50]. Evidence for an active role is discussed below.

In mice, the humoral immune response has been reported to exert a direct effector role against gastrointestinal nematode parasites. Immunity against murine Trichuris muris has been achieved through monoclonal IgA antibody infusion that resulted in the expulsion of the parasites from the gastrointestinal tract [51]. The immune mechanism was thought to be through antibody binding directly to parasite excretion/secretion antigens [51].

Smith et al. [52] were the first to report a relationship between IgA response and reduced worm length following infection with T. circumcincta. They examined the length of all nematodes, including larval stages, to identify inhibited larvae. They found an increase in lymphatic IgA and IgApositive cells in the gastric lymph. Pooling data across age classes produced an extremely strong correlation between the increased IgA response and increased numbers of inhibited larvae. A large study in naturally infected sheep supported this finding by showing that lambs with higher peripheral IgA activity against fourth-stage larvae showed inhibition of a higher proportion of larvae [53].

More recent data have cast doubt on the role of IgA in nematode inhibition [54]. Sheep were trickle-infected, then, challenged with 50,000 T. circumcincta. Parasite development ceased approximately five days after challenge and preceded the peak of IgA activity in the gastric lymph on day 9 . The IgA response was apparently too slow to play a direct role in the inhibition of larval development. However, more research is necessary before firm conclusions can be made. 
The relationship between IgA levels in the gastric lymph and IgA levels at the site of infection in the abomasal mucosa is unknown. In addition, there is density-dependent inhibition of larval development [55]. The mechanism of densitydependent inhibition may differ from that of immunemediated inhibition, and the inhibition observed in this experiment may not have been immune mediated.

In contrast to the uncertain relationship between IgA level and numbers of inhibited larvae, the parasite-specific IgA response is consistently correlated with a reduction in adult worm length in infected animals. In Scottish Blackface sheep matched for age, sex, breed, farm of origin, and parasite exposure history, Stear et al. [49] observed considerable variation in the number of IgA-positive plasma cells and the activity of parasite-specific IgA in the abomasal mucosa. There was a negative correlation between $\operatorname{IgA}$ and worm length, which was stronger for mucosal IgA than for serum IgA. The correlations observed were also stronger against fourth-stage larvae (L4) than against third-stage larvae (L3). Recently, Henderson and Stear [56] showed a direct correlation between mucosal IgA and plasma IgA levels of 0.66 . The negative correlation observed between parasite-specific IgA levels and worm length was likely to have been a direct effect of IgA on the parasite, rather than a change in the quantity of antibody produced in response to changes in worm number [49]. Similar correlations have been observed in Santa Ines, Suffolk, and Ile de France lambs infected by $H$. contortus, Scottish Blackface lambs infected by $H$. contortus, and Churra lambs infected with T. circumcincta [57-59]. In addition, Scottish Blackface lambs that were naturally infected with $T$. circumcincta have shown a similar relationship [53,60].

Stear et al. [49] estimated that approximately $38 \%$ of nematode parasite worm length variation could be accounted for by mucosal IgA activity directed against L4 worms, a value considerably less than the over $90 \%$ estimated by Smith et al. [52]. However, the high value reported by Smith et al. may have been an artefact created by pooling data from sheep of different ages. The level of variation in nematode parasite worm length due to L4 parasite-specific IgA activity has been independently estimated as $\sim 38 \%$ in Churra sheep [59], with similar estimates reported by Sinski et al. [61], Strain and Stear [57], Strain et al. [60], Stear et al. [53], Amarante et al. [58], and Henderson and Stear [56].

In addition to the effects of IgA, two other factors influence the size of adult nematodes: IgA specificity and worm density dependence. Variance analysis in sheep intentionally infected with T. circumcincta [53] indicated that these three components accounted for most of the variation in adult female worm length. This conclusion is consistent with the hypothesis that, in this host-parasite system, IgA is the major host mechanism influencing parasite growth and fecundity. In Strongyloides ratti, the density-dependent response is abolished in immunosuppressed rats [62], which suggests that density dependence is mediated through the immune system in at least some host-parasite systems.

There are several methods by which IgA could influence nematode growth. Parasitic nematodes release a variety of proteases that partially predigest proteins and may also break down antibodies and other mediators of host resistance. Antibodies against these enzymes or other molecules could inhibit enzyme activity and feeding by the parasite [6367]. This appears to be a mechanism underlying the success of vaccination against $\mathrm{H}$-Gal-GP (a galactose-containing glycoprotein complex purified from intestinal membranes of adult $H$. contortus worms) from $H$. contortus $[68,69]$. Alternatively, IgA could interact with eosinophils to control nematode growth and fecundity (see below).

There does not appear to be a consistent association between IgA activity and the number of adult T. circumcincta [49]. There is also no consistent association with the number of $H$. contortus [70-72]. The absence of a relationship suggests that IgA activity does not determine worm numbers.

Hertzberg et al. [73] trickle infected White Alpine lambs with Ostertagia leptospicularis and showed that there was a gradual increase in serum IgA levels during infection. As expected from other species, IgA has a short half-life and IgA activity declined rapidly after anthelminthic treatment. When subsequently challenged with 100,000 infective L3 parasites, the serum IgA level rose rapidly but was observed to decrease earlier than either IgG1 or IgG2.

\section{IgA and Eosinophilia}

Variation in the number of mast cells, globule leucocytes, eosinophils, and IgA plasma cells has been observed in sheep that were infected with nematodes $[49,58]$. Globule leucocytes are derived from subepithelial mast cells $[74,75]$. Stear et al. [49] found that sheep with more mast cells had higher abomasal concentrations of globule leucocytes, eosinophils, IgA plasma cells, and more larval antigen-specific IgA antibody. Henderson and Stear [56] measured the level of IgA and eosinophil numbers in Scottish Blackface lambs over a period of 60 days after challenge and observed that both variables had similar response kinetics. IgA and eosinophil activity peaked at 8-10 days after infection and declined subsequently. Stear et al. [49] measured eosinophil numbers at the end of the experiment during necropsy of the animals while Henderson and Stear [56] measured mucosal eosinophilia over a 60-day period. A similar study using Caribbean hair sheep and wool sheep [19] found that the hair breed had higher serum levels of IgA and IgE in uninfected sheep, and that there were significant differences in IgA, IgE, and tissue eosinophils levels between the two sheep breeds which was negatively correlated with worm counts. IgA levels accounted for $38 \%$ and eosinophil numbers $40 \%$ of the variation in worm length, respectively. In correlation studies that analysed the two variables together, the combination accounted for $53 \%$ of worm length variation. Therefore, it appears that IgA and eosinophilia have a combined or synergistic effect on worm length [56]. Eosinophils have been shown to express receptors for IgA [76, 77], which can be activated by binding of parasite antigen/IgA to IgA cell surface receptors [78]. Therefore, IgA could help target eosinophils to nematodes. Interestingly, eosinophils in mice lack receptors for IgA [76], and this could explain the relative ineffectiveness of eosinophils in some murine models $[79,80]$. 


\section{The Role of IgE in Nematode Resistance}

Increased numbers of mast cells is a hallmark of many nematode infections, and they have been implicated in the control of worm numbers in some but not all infections. For example, mast cells appear crucial for the control of Trichinella spiralis but not for Trichuris muris or Nippostrongylus brasiliensis [81]. Sheep that are resistant to $T$. circumcincta have increased numbers of mast cells or globule leucocytes compared to more susceptible contemporaries [49]. Similarly, mast cells are important for resistance to $H$. contortus $[82,83]$.

As binding of parasite molecules by cell-surface IgE is the major trigger for mast cell degranulation, IgE is implicated by default in resistance to nematode infection. An association between high plasma IgE activity against a high-molecularweight allergen and low egg counts was reported in 20 lambs selected from a group of 72 naturally infected crossbred sheep [84]. A study using lymphatic cannulation to allow continuous assessment of the migrating immune cells from the intestinal mucosa and mesenteric lymph nodes showed differential changes in the expression of IL-5 in the afferent intestinal lymph in two lines of sheep selected for susceptibility or resistance to T. colubriformis [85]. Furthermore, in a parallel study by the same group, the resistant line had higher IgE in lymph than the susceptible line [86]. Naturally infected Texel lambs with high IgE activity against recombinant tropomyosin from $T$. circumcincta also had lower egg counts than lambs with lower IgE responses [87]. An independent study from New Zealand also showed an association between increased IgE activity against an aspartyl protease inhibitor from T. colubriformis and reduced egg counts [88].

\section{Genetic Factors in Gastrointestinal Parasite Immunity}

Quantitative genetic analysis in sheep and cattle has clearly shown that resistance to nematode infection is under genetic control [2, 89-93]. The heritability of a single egg count varies among populations but is usually between 0.2 and 0.4 in animals that have been previously exposed to infection [94]. This is similar to the heritability of milk production in dairy cattle or growth rate in beef cattle and indicates the feasibility of selective breeding [95]. Quantitative trait loci (QTLs) for resistance to the intestinal nematode Heligmosomoides polygyrus were located on mouse chromosomes 1 , $2,8,13,17$, and 19 by Iraqi et al. [32]. Interestingly, one chromosomal region identified by these researchers was the MHC located on mouse chromosome 17. Their observations were confirmed independently by Behnke et al. [33] who found associations between eight immunological traits (FEC at weeks 2, 4, and 6, mucosal mast cell protease 1, granuloma score, IgG1 against L5, and IgG1, and IgE to L4) and QTLs on chromosome 1 and 17 associated with resistance to the H. polygyrus infection. More specifically, the MHC genes, most notably, the class II and TNF regions were significantly associated with gastrointestinal parasite infection.

Davies et al. [29] provided evidence of QTLs located on sheep chromosomes 2, 3, 14, and 20 conferring resistance to infection with T. circumcincta in Scottish Blackface sheep. Analysis of chromosome 20 showed that the MHC region had a statistically significant association with gastrointestinal nematode parasite resistance. QTLs associated with specific IgA activity against nematode parasites were also located on chromosomes 3 and 20. Alleles of the DRB1 in the $\mathrm{MHC}$ class II region have been associated with nematode resistance in several different breeds of sheep [23-25, 96] and cattle [90, 97, 98]. However, in contrast, Beh et al. [99] found no significant linkage of the $\mathrm{MHC}$ in sheep resistance to Trichostrongylus colubriformis. Unfortunately, their study used only a single marker to represent the $\mathrm{MHC}$ region and chromosome 20 in their whole-genome linkage analysis. Beh et al. [99] also applied an additional two markers to a single-point ANOVA and confirmed no linkage to the MHC region. In another linkage study, no significant QTL was found on chromosome 20, for resistance to parasitic nematode infection in sheep [100]. In this study, only four markers were used to represent chromosome 20, of which only two mapped to the MHC region [100]. Recently, a more extensive whole-genome QTL analysis for resistance to $H$. contortus showed, in one family, weak linkage between egg counts and the Ovar-DYA region in the MHC class IIb region [101], consistent with a previous report that associated this region with resistance to T. circumcincta [26].

\section{The Influence of the MHC on Antibody Production}

The role of $\mathrm{MHC}$ in controlling IgA concentrations is supported by several human studies, especially on IgA and combined variable immunodeficiency (CVID). One of the first studies that identified an association between IgA deficiency and the MHC region was by Wilton et al. [102], who found an association between MHC class III genes and IgA deficiency. An increase in frequency of certain HLA haplotypes was observed in deficient patients [102, 103]. A number of studies have since focused on the HLA-A1$B 8$-DR3 haplotype to locate the IgA deficiency locus [104, 105]. An investigation of the HLA-DR3-extended haplotype showed that in the Sardinian population, where a lower prevalence of IgA deficiency exists, the HLA-DR3-B18 haplotype is more common than the $H L A-D R 3-B 8$ haplotype, suggesting that the IgA deficiency susceptibility gene is located in the more common Northern European DR3-B8 haplotypes [106]. The investigation of features common to the different haplotypes was used to establish the region associated with IgA deficiency, and thus far several different studies have placed the susceptibility locus between the class III region $[103,105,107,108]$ and the class II region [109-111].

Polymorphisms in MSH5 have also been shown to be associated with CVID and IgA deficiency in a mouse model and through statistical analysis of human populations [112]. This gene, located within the MHC class III region, is involved in DNA mismatch repair as well as in resolving Holliday junctions that form between homologous DNA strands during meiosis $[113,114]$. However, Guikema et al. [115] observed a large variety of splice variants of MSH5 mRNA (all of which are unlikely to be stable) and suggested 
that MSH5 was nonfunctional and therefore probably does not participate in Ig class switching. Recently, it has been shown that haplotypes of MSH5 are associated with IgA deficiency $[116,117]$ but are not likely to be the causative mutations [117].

\section{Mechanisms Underlying the MHC Association with Nematode Resistance}

Genetic variation in the mouse MHC has long been associated with resistance to nematode infection [118] and with the specificity of antibody responses [119]. It has been reported that the helminth Nippostrongylus brasiliensis may possibly be able to suppress MHC class II molecule expression as an evasive mechanism [120]. Likewise, for sheep, it has been shown that the parasite T. colubriformis seems to be capable of downregulating several immune genes, particularly $D R B 1$ and $D R A$, in afferent lymph migratory cells [121]. In the mouse model infected with Strongyloides venezuelensis, class II $^{-/-}$animals were more susceptible to infection (based on increase in FEC and elimination of worms) than wild-type and class $\mathrm{I}^{-1-}$ mice [31]. In addition, parasite-specific IgM, IgA, and IgG were also significantly reduced in class II ${ }^{-/-}$ mice. This study concluded that class II MHC expression was essential to induce a Th2 response against $S$. venezuelensis infection and class I expression was not [31]. Interestingly and somewhat contradictory to the findings discussed above [121], it has been shown that mice strains that lack $I-E$, a homologue of DRB1, in their MHC class II region are more resistant [122].

In a comparative study using bovine cDNA microarray analysis of duodenum tissue from an outbred population of resistant and susceptible lambs (which had been subjected to two natural challenges with a range of gastrointestinal parasites), increased expression was observed in a range of genes [18]. Upregulated genes included $D Q B 1, D R A$, and $D Q A 1$ from the MHC class II region [18]. This observation highlights key differences between resistant and susceptible animals in the early immune response to gastrointestinal nematodes. In a separate microarray study, differences were observed in gene expression profiles of hair and wool sheep that had been infected with $H$. contortus [19]. Elevated expression of the MHC class II DM $\beta$-chain precursor gene was observed in lymph node tissue of the wool breed. However, no significant change in the expression of this or any other MHC-related gene was observed in abomasal tissue [19]. In another study, using transcriptional profiling of duodenum tissue samples from resistant and susceptible sheep [20], up-regulation of MHC class II genes Ovar $D Q A 1$, Ovar DQB1, and Ovar DRA was observed in resistant animals. Subsequent RT-PCR analysis of Ovar DQA1 showed an average 8.4-fold greater expression in resistant animals than in susceptible animals. Further analysis using GO terms highlighted the significant association between genes highly expressed in resistant animals with terms such as MHC class II activity and exogenous antigen processing and presentation [20]. Furthermore, the frequency of Ovar DQA1 haplotypes differed between animals from the resistant and susceptible selection lines, with an increase in Ovar $D Q A 1^{*}$ Null in susceptible animals from both Perendale and Romney sheep lines. In Perendale sheep, the frequency of Ovar $D Q A 1^{*} 0101$ and $D Q A 1^{*} 0402$ alleles was increased in resistant animals and Ovar DQA1*0103 increased in the susceptible line. However, these observations seemingly contradict earlier findings by the same group, in which no increase was observed in the expression of either MHC class II genes nor any association was found with antigen presentation or processing [123]. Interestingly, a significant increase in expression of a MHC class I gene (HLA-A orthologue) in resistant animals was also observed, indicating possible crosstalk between the different responses. Recently, Forrest and colleagues [21] conversely demonstrated no evidence of an interbreed effect of the Ovar-DQA1*Null allele on total faecal egg counts. However, the Ovar-DQA1*Null appeared to have a significant effect when the analysis was performed within breeds [21].

In a statistical examination of the relationship between MHC polymorphism and parasitological traits in Scottish Blackface sheep, the resistant allele G2 at the DRB1 locus was significantly associated with decreased egg counts and decreased numbers of adult T. circumcincta [96]. However, no apparent correlation was observed with adult female parasite length. Hence, the mechanism by which the MHC influences egg counts may operate through the control of worm number and not by controlling nematode fecundity. There are several possible mechanisms but possibly specific class II molecules direct responses to specific peptides, and these responses may play a direct role in protection.

Another possibility is that the observed associations in livestock are a consequence of heterozygote advantage [96]. Heterozygote advantage has complex effects on the power of statistical analyses to detect specific allele effects [27]. As the frequency of an allele increases in a population, an increasing proportion of homozygous sheep will be present and thus the average effect of the specific allele will decline. Also, an allele that is very rare in a population will be present in too few animals to show a significant effect. Conversely, when the allele is very common in the population, its average effect is quite small making its contribution to reduced egg counts difficult to detect. Consequently, only alleles within a narrow frequency range will show effects on parasite resistance. Interestingly, the allele most strongly associated with resistance in Scottish Blackface sheep fell within the narrow detection window, and the most common allele was also associated with the most susceptible animals as predicted by heterozygote advantage. There was also more direct evidence: Heterozygous sheep had lower egg counts following natural T. circumcincta infection [96].

Heterozygote advantage is a particularly appealing mechanism for explaining the IgE response to parasites. The specificity of IgE responses is relatively unimportant for mast cell degranulation if the target molecule is soluble and large enough to promote cross-linking of IgE receptors. Therefore, a heterozygote advantage that leads to increased IgE concentrations is more supported than a model of determinant selection (i.e., a direct role of the allele in determining levels of IgE). 
TABLE 1: Summary of studies that have implicated the MHC in resistance to gastointestinal parasites.

\begin{tabular}{|c|c|c|c|c|}
\hline Species & Parasite species & Method & MHC association & Reference \\
\hline \multirow[t]{10}{*}{ Sheep (Ovis aries) } & mixed & Microarray & $D Q B 1, D R A, D Q A 1$ & {$[18]$} \\
\hline & H. contortus & Microarray & $D M B$ & {$[19]$} \\
\hline & mixed & Microarray & $D Q A 1^{*} N u l l, D Q B 1, D R A$ & {$[20]$} \\
\hline & mixed & PCR analysis & DQA1*Null & {$[21]$} \\
\hline & mixed & $\mathrm{PCR} /$ sequencing & $D Q A 1^{*} 0101, D Q A 1^{*} 0402$ & {$[20]$} \\
\hline & mixed & $\mathrm{PCR} /$ sequencing & $D R B 1$ & {$[22,23]$} \\
\hline & mixed & PCR & DRB microsatellite & {$[23]$} \\
\hline & $\begin{array}{l}\text { Teladorsagia } \\
\text { circumcincta }\end{array}$ & PCR/sequencing & $D R B 1$ & [24-27] \\
\hline & H. contortus & PCR/sequencing & $D R B 1, O M H C 1$ & {$[28]$} \\
\hline & $\begin{array}{l}\text { Teladorsagia } \\
\text { circumcincta }\end{array}$ & Linkage & Class IIb region & {$[29]$} \\
\hline Sheep (Ovis canadensis) & $n / a$ & $\begin{array}{l}\text { Population analysis } \\
\text { PCR/sequencing }\end{array}$ & $D R B 1$ & {$[30]$} \\
\hline \multirow[t]{2}{*}{ Mouse (Mus musculus) } & S. venezuelensis & Knock out & Class II & {$[31]$} \\
\hline & H. polygyrus & Linkage & Class II region & {$[32,33]$} \\
\hline $\begin{array}{l}\text { Striped mouse (Rhabdomys } \\
\text { pumilio) }\end{array}$ & mixed & PCR/sequencing & $D R B$ & {$[34]$} \\
\hline $\begin{array}{l}\text { Yellow necked mouse (Apodemus } \\
\text { flavicollis) }\end{array}$ & mixed & PCR/sequencing & $D R B$ & {$[35]$} \\
\hline $\begin{array}{l}\text { Gray mouse lemur } \\
\text { (Microcebusmurinus) }\end{array}$ & mixed & PCR/sequencing & $D R B$ & {$[36]$} \\
\hline
\end{tabular}

Charbonnel and Pemberton [124] examined both MHC and neutral loci in free-living Soay sheep that were infected by $T$. circumcincta in St Kilda (Scotland). Over eight years, lower levels of temporal genetic differentiation were observed at MHC loci compared with neutral loci, consistent with balancing selection activity at the MHC loci [124]. These observations confirmed earlier work by Paterson [125] but have not been supported by subsequent research [126]. Significant studies showing positive associations between genes within the MHC and gastrointestinal parasites are summarised in Table 1.

\section{Conclusions}

There is no single mechanism of nematode resistance in sheep. Resistance to gastrointestinal nematodes involves the control of worm growth as well as worm numbers. The negative correlation between parasite-specific IgA levels and worm length has been well established by many research groups in different breeds of sheep infected by different gastrointestinal parasites. The control of worm numbers involves mast cells in some but not all host-nematode systems. There is a genetic component to nematode resistance, and the $\mathrm{MHC}$ is one of the most important components of genetic resistance. QTL analyses have shown a link between the MHC region and FEC in mouse models, as well as in sheep and cattle. The influence of the class II region on parasite resistance has been shown in experimental models as well as by microarray analysis.

Despite the large number of studies that confirmed these relationships, there are other studies in which contradictory results reject these hypotheses. However, correlation studies may generate a complex heterogeneity of results because of the large variety of gastrointestinal nematode parasites and differences in environmental conditions, nutritional status of animals, and geographical locations. Another complication is that the relationship between gene expression from the $\mathrm{MHC}$ region, IgA activity, and their effects on parasites is often considered individually rather than as interconnecting multilevel interactions.

\section{Acknowledgment}

M. J. Stear thanks the BBSRC, QMS, and Genesis/Faraday for support.

\section{References}

[1] L. J. E. Karlsson and J. C. Greeff, "Selection response in fecal worm egg counts in the Rylington Merino parasite resistant flock," Australian Journal of Experimental Agriculture, vol. 46, no. 6-7, pp. 809-811, 2006. 
[2] K. E. Kemper, D. G. Palmer, S. M. Liu, J. C. Greeff, S. C. Bishop, and L. J. E. Karlsson, "Reduction of faecal worm egg count, worm numbers and worm fecundity in sheep selected for worm resistance following artificial infection with Teladorsagia circumcincta and Trichostrongylus colubriformis," Veterinary Parasitology, vol. 171, pp. 238-246, 2010.

[3] C. A. Morris, T. G. Watson, S. A. Bisset, A. Vlassoff, and P. G. C. Douch, "Breeding sheep in New Zealand for resistance or resilience to nematode parasites," in Breeding for Resistance to Infectious Diseases of Small Ruminants, G. D. Gray, R. R. Woolaston, and B. D. Eaton, Eds., pp. 77-98, ACIAR Monograph, Canberra, Australia, 2000.

[4] R. R. Woolaston and R. G. Windon, "Selection of sheep for response to Trichostrongylus colubriformis colubriformis larvae: genetic parameters," Animal Science, vol. 73, no. 1, pp. 41-48, 2001.

[5] J. C. McEwan, K. G. Dodds, G. J. Greer et al., "Genetic estimates for parasite resistance traits in sheep and their correlations with production traits," New Zealand Journal of Zoology, vol. 22, p. 177, 1995.

[6] S. A. Bisset, A. Vlassoff, C. A. Morris, B. R. Southey, R. L. Baker, and A. G. H. Parker, "Heritability of and genetic correlations among faecal egg counts and productivity traits in Romney sheep," New Zealand Journal of Agricultural Research, vol. 35, pp. 51-58, 1992.

[7] S. J. Eady, R. R. Woolaston, R. P. Lewer, H. W. Raadsma, A. A. Swan, and R. W. Ponzoni, "Resistance to nematode parasites in Merino sheep: correlation with production traits," Australian Journal of Agricultural Research, vol. 49, no. 8, pp. 1201-1211, 1998.

[8] S. C. Bishop, K. Bairden, Q. A. McKellar, M. Park, and M. J. Stear, "Genetic parameters for faecal egg count following mixed, natural, predominantly Ostertagia circumcincta infection and relationships with live weight in young lambs," Animal Science, vol. 63, no. 3, pp. 423-428, 1996.

[9] M. J. Stear, K. Bairden, J. L. Duncan et al., "How hosts control worms," Nature, vol. 389, no. 6646, p. 27, 1997.

[10] J. Bouix, J. Krupinski, R. Rzepecki et al., "Genetic resistance to gastrointestinal nematode parasites in polish long-wool sheep," International Journal for Parasitology, vol. 28, no. 11, pp. 1797-1804, 1998.

[11] M. J. Stear, S. C. Bishop, N. G. Henderson, and I. Scott, "A key mechanism of pathogenesis in sheep infected with the nematode Teladorsagia circumcincta," Animal Health Research Reviews, vol. 4, no. 1, pp. 45-52, 2003.

[12] J. M. Behnke, F. Iraqi, D. Menge, R. L. Baker, J. Gibson, and D. Wakelin, "Chasing the genes that control resistance to gastrointestinal nematodes," Journal of Helminthology, vol. 77, no. 2, pp. 99-109, 2003.

[13] W. I. Khan, "Physiological changes in the gastrointestinal tract and host protective immunity: learning from the mouse-Trichinella spiralis model," Parasitology, vol. 135, no. 6, pp. 671-682, 2008.

[14] G. Mulcahy, S. O’Neill, S. Donnelly, and J. P. Dalton, "Helminths at mucosal barriers-interaction with the immune system," Advanced Drug Delivery Reviews, vol. 56, no. 6, pp. 853-868, 2004.

[15] D. W. K. Acheson and S. Luccioli, "Microbial-gut interactions in health and disease. Mucosal immune responses," Best Practice and Research Clinical Gastroenterology, vol. 18, pp. 387-404, 2004.

[16] R. M. Maizels and M. Yazdanbakhsh, "Immune regulation by helminth parasites: cellular and molecular mechanisms," Nature Reviews Immunology, vol. 3, no. 9, pp. 733-744, 2003.
[17] C. A. Janeway, P. Travers, M. Walport, and M. Schlomchik, Immunobiology: The Immune System in Health and Disease, Churchill Levingstone, Edinburgh, UK, 2001.

[18] C. Diez-Tascón, O. M. Keane, T. Wilson et al., "Microarray analysis of selection lines from outbred populations to identify genes involved with nematode parasite resistance in sheep," Physiological Genomics, vol. 21, pp. 59-69, 2005.

[19] K. M. MacKinnon, J. L. Burton, A. M. Zajac, and D. R. Notter, "Microarray analysis reveals difference in gene expression profiles of hair and wool sheep infected with Haemonchus contortus," Veterinary Immunology and Immunopathology, vol. 130, no. 3-4, pp. 210-220, 2009.

[20] O. M. Keane, K. G. Dodds, A. M. Crawford, and J. C. McEwan, "Transcriptional profiling of Ovis aries identifies Ovar-DQA1 allele frequency differences between nematoderesistant and susceptible selection lines," Physiological Genomics, vol. 30, no. 3, pp. 253-261, 2007.

[21] R. H.J. Forrest, H. Zhou, Q. Fang, A. Smyth, C. M. Frampton, and J. G.H. Hickford, "No evidence for a universal association between variation in faecal egg count for a mixed fieldchallenge of gastrointestinal parasites and the presence of the Ovar-DQA1 null haplotype in sheep," Veterinary Immunology and Immunopathology, vol. 135, no. 3-4, pp. 303-305, 2010.

[22] S. Paterson, K. Wilson, and J. M. Pemberton, "Major histocompatibility complex variation associated with juvenile survival and parasite resistance in a large unmanaged ungulate population (Ovis aries L.)," Proceedings of the National Academy of Sciences of the United States of America, vol. 95, no. 7, pp. 3714-3719, 1998.

[23] P. M. Outteridge, L. Andersson, P. G. C. Douch et al., "The PCR typing of MHC-DRB genes in the sheep using primers for an intronic microsatellite: application to nematode parasite resistance," Immunology and Cell Biology, vol. 74, no. 4, pp. 330-336, 1996.

[24] F. W. Schwaiger, D. Gostomski, M. J. Stear et al., "An ovine major histocompatibility complex DRB1 allele is associated with low faecal egg counts following natural, predominantly Ostertagia circumcincta infection," International Journal for Parasitology, vol. 25, no. 7, pp. 815-822, 1995.

[25] G. Sayers, B. Good, J. P. Hanrahan, M. Ryan, J. M. Angles, and T. Sweeney, "Major Histocompatibility Complex DRB1 gene: its role in nematode resistance in Suffolk and Texel sheep breeds," Parasitology, vol. 131, no. 3, pp. 403-409, 2005.

[26] J. Buitkamp, P. Filmether, M. J. Stear, and J. T. Epplen, "Class I and class II major histocompatibility complex alleles are associated with faecal egg counts following natural, predominantly Ostertagia ciucumcincta infection," Parasitology Research, vol. 82, no. 8, pp. 693-696, 1996.

[27] M. J. Stear, A. Belch, K. Donskow-Schmelter et al., "Detection of genes with moderate effects on disease resistance using ovine mhc and resistance to nematodes as an example," Veterinary Immunology and Immunopathology, vol. 120, no. 1-2, pp. 3-9, 2007.

[28] J. A. Figueroa Castillo, R. D.M. Medina, J. M.B. Villalobos et al., "Association between major histocompatibility complex microsatellites, fecal egg count, blood packed cell volume and blood eosinophilia in Pelibuey sheep infected with Haemonchus contortus," Veterinary Parasitology. In press.

[29] G. Davies, M. J. Stear, M. Benothman et al., "Quantitative trait loci associated with parasitic infection in Scottish Blackface sheep," Heredity, vol. 96, no. 3, pp. 252-258, 2006. 
[30] G. A. Gutierrez-Espeleta, P. W. Hedrick, S. T. Kalinowski, D. Garrigan, and W. M. Boyce, "Is the decline of desert bighorn sheep from infectious disease the result of low MHC variation?" Heredity, vol. 86, no. 4, pp. 439-450, 2001.

[31] R. M. Rodrigues, N. M. Silva, A. L.R. Gonçalves et al., "Major histocompatibility complex (MHC) class II but not MHC class i molecules are required for efficient control of Strongyloides venezuelensis infection in mice," Immunology, vol. 128, no. 1, pp. e432-e441, 2009.

[32] F. A. Iraqi, J. M. Behnke, D. M. Menge et al., "Chromosomal regions controlling resistance to gastro-intestinal nematode infections in mice," Mammalian Genome, vol. 14, no. 3, pp. 184-191, 2003.

[33] J. M. Behnke, F. A. Iraqi, J. M. Mugambi et al., "High resolution mapping of chromosomal regions controlling resistance to gastrointestinal nematode infections in an advanced intercross line of mice," Mammalian Genome, vol. 17, no. 6, pp. 584-597, 2006.

[34] G. Froeschke and S. Sommer, "MHC class II DRB variability and parasite load in the striped mouse (Rhabdomys pumilio) in the Southern Kalahari," Molecular Biology and Evolution, vol. 22, no. 5, pp. 1254-1259, 2005.

[35] Y. Meyer-Lucht and S. Sommer, "MHC diversity and the association to nematode parasitism in the yellow-necked mouse (Apodemus flavicollis)," Molecular Ecology, vol. 14, no. 7, pp. 2233-2243, 2005.

[36] J. Schad, J. U. Ganzhorn, and S. Sommer, "Parasite burden and constitution of major histocompatibility complex in the Malagasy mouse lemur, Microcebus murinus," Evolution, vol. 59, no. 2, pp. 439-450, 2005.

[37] R. K. Grencis, J. Riedlinger, and D. Wakelin, "L3T4-positive $\mathrm{T}$ lymphoblasts are responsible for transfer of immunity to Trichinella spiralis in mice," Immunology, vol. 56, no. 2, pp. 213-218, 1985.

[38] H. L. Rotman, S. Schnyder-Candrian, P. Scott, T. J. Nolan, G. A. Schad, and D. Abraham, "IL-12 eliminates the Th-2 dependent protective immune response of mice to larval Strongyloides stercoralis," Parasite Immunology, vol. 19, no. 1, pp. 29-39, 1997.

[39] H. S. Gill, D. L. Watson, and M. R. Brandon, "Monoclonal antibody to $\mathrm{CD}^{+} \mathrm{T}$ cells abrogates genetic resistance to Haemonchus contortus in sheep," Immunology, vol. 78, no. 1, pp. 43-49, 1993.

[40] M. J. Stear, S. Strain, and S. C. Bishop, "How lambs control infection with Ostertagia circumcincta," Veterinary Immunology and Immunopathology, vol. 72, no. 1-2, pp. 213-218, 1999.

[41] M. J. Stear, S. Strain, and S. C. Bishop, "Mechanisms underlying resistance to nematode infection," International Journal for Parasitology, vol. 29, no. 1, pp. 51-56, 1999.

[42] M. J. Stear and S. C. Bishop, "The curvilinear relationship between worm length and fecundity of Teladorsagia circumcincta," International Journal for Parasitology, vol. 29, no. 5, pp. 777-780, 1999.

[43] D. Wakelin, "Rodent models of genetic resistance to parasite infections," in Breeding for Disease Resistance in Farm Animals, R. E. F. Axford, S. C. Bishop, F. W. Nicholas, and J. B. Owen, Eds., pp. 107-126, CAB International, Wallingford, Wash, USA, 2nd edition, 2000.

[44] K. Kanobana, H. W. Ploeger, and L. Vervelde, "Immune expulsion of the trichostrongylid Cooperia oncophora is associated with increased eosinophilia and mucosal IgA," International Journal for Parasitology, vol. 32, no. 11, pp. 1389-1398, 2002.
[45] T. Inaba, H. Sato, and H. Kamiya, "Monoclonal IgA antibody-mediated expulsion of Trichinella from the intestine of mice," Parasitology, vol. 126, no. 6, pp. 591-598, 2003.

[46] C. P. Wilkes, C. Bleay, S. Paterson, and M. E. Viney, "The immune response during a Strongyloides ratti infection of rats," Parasite Immunology, vol. 29, no. 7, pp. 339-346, 2007.

[47] S. Yanming, Y. Ruofeng, C. I. Muleke, Z. Guangwei, X. Lixin, and L. Xiangrui, "Vaccination of goats with recombinant galectin antigen induces partial protection against Haemonchus contortus infection," Parasite Immunology, vol. 29, no. 6, pp. 319-326, 2007.

[48] K. Matsuzawa, M. Abe, T. Shirakura, W. H. Zhao, and F. Nakamura, "Spontaneous worm expulsion and intestinal IgA response in mice infected by Vampirolepis nana," Parasitology International, vol. 57, no. 4, pp. 512-514, 2008.

[49] M. J. Stear, S. C. Bishop, M. Doligalska et al., "Regulation of egg production, worm burden, worm length and worm fecundity by host responses in sheep infected with Ostertagia circumcincta," Parasite Immunology, vol. 17, no. 12, pp. 643-652, 1995.

[50] M. E. Lamm, "Interaction of antigens and antibodies at mucosal surfaces," Annual Review of Microbiology, vol. 51, pp. 311-340, 1997.

[51] T. I. A. Roach, K. J. Else, D. Wakelin, D. J. McLaren, and R. K. Grencis, "Trichuris muris: antigen recognition and transfer of immunity in mice by IgA monoclonal antibodies," Parasite Immunology, vol. 13, no. 1, pp. 1-12, 1991.

[52] W. D. Smith, F. Jackson, E. Jackson, and J. Williams, "Age immunity to Ostertagia circumcincta: comparison of the local immune responses of $41 / 2$-and 10-month-old lambs," Journal of Comparative Pathology, vol. 95, no. 2, pp. 235-245, 1985.

[53] M. J. Stear, K. Bairden, G. T. Innocent, S. Mitchell, S. A. J. Strain, and S. C. Bishop, "The relationship between IgA activity against fourth-stage larvae and density-dependent effects on the number of fourth-stage larvae of Teladorsagia circumcincta in naturally infected sheep," Parasitology, vol. 129, pp. 363-369, 2004.

[54] A. M. Halliday, C. M. Routledge, S. K. Smith, J. B. Matthews, and W. D. Smith, "Parasite loss and inhibited development of Teladorsagia circumcincta in relation to the kinetics of the local IgA response in sheep," Parasite Immunology, vol. 29, no. 8, pp. 425-434, 2007.

[55] J. D. Dunsmore, "Retarded development of Ostertagia species in sheep," Nature, vol. 186, no. 4729, pp. 986-987, 1960.

[56] N. G. Henderson and M. J. Stear, "Eosinophil and IgA responses in sheep infected with Teladorsagia circumcincta," Veterinary Immunology and Immunopathology, vol. 112, no. 1-2, pp. 62-66, 2006.

[57] S. A. J. Strain and M. J. Stear, "The influence of protein supplementation on the immune response to Haemonchus contortus," Parasite Immunology, vol. 23, no. 10, pp. 527-531, 2001.

[58] A. F. T. Amarante, P. A. Bricarello, J. F. Huntley, L. P. Mazzolin, and J. C. Gomes, "Relationship of abomasal histology and parasite-specific immunoglobulin A with the resistance to Haemonchus contortus infection in three breeds of sheep," Veterinary Parasitology, vol. 128, no. 1-2, pp. 99-107, 2005.

[59] M. Martínez-Valladares, M. P. Vara-Del Río, M. A. CruzRojo, and F. A. Rojo-Vázquez, "Genetic resistance to Teladorsagia circumcincta: IgA and parameters at slaughter in Churra sheep," Parasite Immunology, vol. 27, no. 6, pp. 213-218, 2005. 
[60] S. A. J. Strain, S. C. Bishop, N. G. Henderson et al., "The genetic control of IgA activity against Teladorsagia circumcincta and its association with parasite resistance in naturally infected sheep," Parasitology, vol. 124, no. 5, pp. 545-552, 2002.

[61] E. Sinski, K. Bairden, J. L. Duncan et al., "Local and plasma antibody responses to the parasitic larval stages of the abomasal nematode Ostertagia circumcincta," Veterinary Parasitology, vol. 59, no. 2, pp. 107-118, 1995.

[62] S. Paterson and M. E. Viney, "Host immune responses are necessary for density dependence in nematode infections," Parasitology, vol. 125, no. 3, pp. 283-292, 2002.

[63] A. C. Chandler, "Experiments on resistance of rats to superinfection with the nematode, Nippostrongylus muris," American Journal of Epidemiology, vol. 16, no. 3, pp. 750-782, 1932.

[64] A. C. Chandler, "Studies on the nature of immunity to intestinal helminths. I. The local nature of the immunity of white rats to Nippostrongylus infection," American Journal of Epidemiology, vol. 22, pp. 157-168, 1935.

[65] A. C. Chandler, "Studies on the nature of immunity to intestinal helminths. II. A study of the correlation between degree of resistance of white rats to Nippostrongylus and interval between infections," American Journal of Epidemiology, vol. 22, pp. 243-256, 1935.

[66] A. C. Chandler, "Studies on the nature of immunity to intestinal helminths. III. Renewal of growth and egg production in Nippostrongylus after transfer from immune to non-immune rats," American Journal of Epidemiology, vol. 23, pp. 46-54, 1936.

[67] A. C. Chandler, "Studies on the nature of immunity to intestinal helminths. IV. The inter-relationships between parenteral and intestinal immunity in rats infected with Nippostrongylus," American Journal of Epidemiology, vol. 24, pp. 129-144, 1936.

[68] D. P. Knox, D. L. Redmond, G. F. Newlands, P. J. Skuce, D. Pettit, and W. D. Smith, "The nature and prospects for gut membrane proteins as vaccine candidates for Haemonchus contortus and other ruminant trichostrongyloids," International Journal for Parasitology, vol. 33, no. 11, pp. 1129-1137, 2003.

[69] S. e. Ekoja and W. D. Smith, "Antibodies from sheep immunized against Haemonchus contortus with H-gal-GP inhibit the haemoglobinase activity of this protéase complex," Parasite Immunology, vol. 32, pp. 731-738, 2010.

[70] V. M. Bowles, M. R. Brandon, and E. Meeusen, "Characterization of local antibody responses to the gastrointestinal parasite Haemonchus contortus," Immunology, vol. 84, no. 4, pp. 669-674, 1995.

[71] H. D. F. H. Schallig, M. A. W. Van Leeuwen, and W. M. L. Hendrikx, "Isotype-specific serum antibody responses of sheep to Haemonchus contortus antigens," Veterinary Parasitology, vol. 56, no. 1-3, pp. 149-162, 1995.

[72] M. T. Gómez-Muñoz, M. Cuquerella, L. A. Gómez-Iglesias et al., "Serum antibody response of Castellana sheep to Haemonchus contortus infection and challenge: relationship to abomasal worm burdens," Veterinary Parasitology, vol. 81, no. 4, pp. 281-293, 1999.

[73] H. Hertzberg, H. D. F. H. Schallig, and P. Deplazes, "Development of a protective immunity against Ostertagia leptospicularis in trickle-infected sheep and parallel changes of serum gastrin, pepsinogen and antibody levels," Veterinary Journal, vol. 157, no. 2, pp. 148-159, 1999.
[74] M. Murray, H. R. P. Miller, and W. F. H. Jarrett, "The globule leukocyte and its derivation from the subepithelial mast cell," Laboratory Investigation, vol. 19, pp. 222-234, 1968.

[75] J. F. Huntley, B. McGorum, G. F. J. Newlands, and H. R. P. Miller, "Granulated intraepithelial lymphocytes: their relationship to mucosal mast cells and globule leucocytes in the rat," Immunology, vol. 53, no. 3, pp. 525-535, 1984.

[76] M. Van Egmond, C. A. Damen, A. B. Van Spriel, G. Vidarsson, E. Van Garderen, and J. G. J. Van De Winkel, "IgA and the IgA Fc receptor," Trends in Immunology, vol. 22, no. 4, pp. 205-211, 2001.

[77] J. M. Woof and M. A. Ken, "The function of immunoglobulin A in immunity," Journal of Pathology, vol. 208, no. 2, pp. 270-282, 2006.

[78] C. Prussin and D. D. Metcalfe, "IgE, mast cells, basophils, and eosinophils," Journal of Allergy and Clinical Immunology, vol. 111, no. 2, pp. S486-S494, 2003.

[79] B. De Andres, E. Rakasz, M. Hagen et al., "Lack of Fc- $\varepsilon$ receptors on murine eosinophils: implications for the functional significance of elevated IgE and eosinophils in parasitic infections," Blood, vol. 89, no. 10, pp. 3826-3836, 1997.

[80] C. A. Behm and K. S. Ovington, "The role of eosinophils in parasitic helminth infections: insights from genetically modified mice," Parasitology Today, vol. 16, no. 5, pp. 202-209, 2000.

[81] C. E. Lawrence, "Is there a common mechanism of gastrointestinal nematode expulsion?" Parasite Immunology, vol. 25, no. 5, pp. 271-281, 2003.

[82] H. D. F. H. Schallig, M. A. W. Van Leeuwen, and A. W. C. A. Cornelissen, "Protective immunity induced by vaccination with two Haemonchus contortus excretory secretory proteins in sheep," Parasite Immunology, vol. 19, no. 10, pp. 447-453, 1997.

[83] H. D. F. H. Schallig, "Immunological responses of sheep to Haemonchus contortus," Parasitology, vol. 120, pp. S63-S72, 2000.

[84] J. F. Huntley, J. Redmond, W. Welfare et al., "Studies on the immunoglobulin E responses to Teladorsagia circumcincta in sheep: purification of a major high molecular weight allergen," Parasite Immunology, vol. 23, no. 5, pp. 227-235, 2001.

[85] A. Pernthaner, S. A. Cole, L. Morrison, and W. R. Hein, "Increased expression of interleukin-5 (IL-5), IL-13, and tumor necrosis factor alpha genes in intestinal lymph cells of sheep selected for enhanced resistance to nematodes during infection with Trichostronglus colubriformis," Infection and Immunity, vol. 73, no. 4, pp. 2175-2183, 2005.

[86] A. Pernthaner, R. J. Shaw, M. M. McNeill, L. Morrison, and W. R. Hein, "Total and nematode-specific IgE responses in intestinal lymph of genetically resistant and susceptible sheep during infection with Trichostrongylus colubriformis," Veterinary Immunology and Immunopathology, vol. 104, no. 1-2, pp. 69-80, 2005.

[87] L. Murphy, P. D. Eckersall, S. C. Bishop et al., "Genetic variation among lambs in peripheral IgE activity against the larval stages of Teladorsagia circumcincta," Parasitology, pp. 1-12, 2010.

[88] R. J. Shaw, M. M. McNeill, D. R. Maass et al., "Identification and characterisation of an aspartyl protease inhibitor homologue as a major allergen of Trichostrongylus colubriformis," International Journal for Parasitology, vol. 33, no. 11, pp. 1233-1243, 2003. 
[89] S. A. Bisset, A. Vlassoff, C. A. Morris, B. R. Southey, R. L. Baker, and A. G. H. Parker, "Heritability of and genetic correlations among faecal egg counts and productivity traits in Romney sheep," New Zealand Journal of Agricultural Research, vol. 35, pp. 51-58, 1992.

[90] M. J. Stear, D. J. S. Hetzel, S. C. Brown, L. J. Gershwin, M. J. Mackinnon, and F. W. Nicholas, "The relationships among ecto- and endoparasite levels, Class I antigens of the bovine major histocompatibility system, immunoglobulin E levels and weight gain," Veterinary Parasitology, vol. 34, no. 4, pp. 303-321, 1990.

[91] M. J. Stear and M. Murray, "Genetic resistance to para-sitic disease: particularly of resistance in ruminants to gastrointestinal nematodes," Veterinary Parasitology, vol. 54, no. 1-3, pp. 161-176, 1994.

[92] M. J. Stear, L. Fitton, G. T. Innocent, L. Murphy, K. Rennie, and L. Matthews, "The dynamic influence of genetic variation on the susceptibility of sheep to gastrointestinal nematode infection," Journal of the Royal Society Interface, vol. 4, no. 16, pp. 767-776, 2007.

[93] S. C. Bishop, F. Jackson, R. L. Coop, and M. J. Stear, "Genetic parameters for resistance to nematode infections in Texel lambs and their utility in breeding programmes," Animal Science, vol. 78, no. 2, pp. 185-194, 2004.

[94] M. J. Stear, K. Bairden, S. C. Bishop et al., "The genetic basis of resistance to Ostertagia circumcincta in lambs," Veterinary Journal, vol. 154, no. 2, pp. 111-119, 1997.

[95] M. J. Stear, S. C. Bishop, B. A. Mallard, and H. Raadsma, "The sustainability, feasibility and desirability of breeding livestock for disease resistance," Research in Veterinary Science, vol. 71, no. 1, pp. 1-7, 2001.

[96] M. J. Stear, G. T. Innocent, and J. Buitkamp, “The evolution and maintenance of polymorphism in the major histocompatibility complex," Veterinary Immunology and Immunopathology, vol. 108, no. 1-2, pp. 53-57, 2005.

[97] M. J. Stear, T. J. Tierney, F. C. Baldock, S. C. Brown, F. W. Nicholas, and T. H. Rudder, "Class I antigens of the bovine major histocompatibility system are weakly associated with variation in faecal worm egg counts in naturally infected cattle," Animal Genetics, vol. 19, no. 2, pp. 115-122, 1988.

[98] L. C. Gasbarre, E. A. Leighton, and C. J. Davies, "Influ-ence of host genetics upon antibody responses against gastrointestinal nematode infections in cattle," Veterinary Parasitology, vol. 46, no. 1-4, pp. 81-91, 1993.

[99] K. J. Beh, D. J. Hulme, M. J. Callaghan et al., "A genome scan for quantitative trait loci affecting resistance to Trichostrongylus colubriformis in sheep," Animal Genetics, vol. 33, no. 2, pp. 97-106, 2002.

[100] A. M. Crawford, K. A. Paterson, K. G. Dodds et al., "Discovery of quantitative trait loci for resistance to parasitic nematode infection in sheep: I. Analysis of outcross pedigrees," BMC Genomics, vol. 7, article 178, 2006.

[101] K. Marshall, J. F. Maddox, S. H. Lee et al., "Genetic mapping of quantitative trait loci for resistance to Haemonchus contortus in sheep," Animal Genetics, vol. 40, no. 3, pp. 262-272, 2009.

[102] A. N. Wilton, T. J. Cobain, and R. L. Dawkins, "Family studies of IgA deficiency," Immunogenetics, vol. 21, no. 4, pp. 333-342, 1985.

[103] F. M. Schaffer, J. Palermos, Z. B. Zhu, B. O. Barger, M. D. Cooper, and J. E. Volanakis, "Individuals with IgA deficiency and common variable immunodeficiency share polymorphisms of major histocompatibility complex class III genes," Proceedings of the National Academy of Sciences of the United States of America, vol. 86, no. 20, pp. 8015-8019, 1989.

[104] A. Reil, G. Bein, H. K. G. Machulla, B. Sternberg, and M. Seyfarth, "High-resolution DNA typing in immunoglobulin A deficiency confirms a positive association with DRB1*0301, DQB1*02 haplotypes," Tissue Antigens, vol. 50, no. 5, pp. 501-506, 1997.

[105] H. W. Schroeder, Z. B. Zhu, R. E. March et al., "Susceptibility locus for IgA deficiency and common variable immunodeficiency in the HLA-DR3, -B8, -A1 haplotypes," Molecular Medicine, vol. 4, no. 2, pp. 72-86, 1998.

[106] F. Cucca, Z. B. Zhu, A. Khanna et al., "Evaluation of IgA deficiency in Sardinians indicates a susceptibility gene is encoded within the HLA class III region," Clinical and Experimental Immunology, vol. 111, no. 1, pp. 76-80, 1998.

[107] V. B. Matthews, C. S. Witt, M. A. H. French et al., "Central MHC genes affect IgA levels in the human: reciprocal effects in IgA deficiency and IgA nephropathy," Human Immunology, vol. 63, no. 5, pp. 424-433, 2002.

[108] J. E. Volanakis, Z. B. Zhu, F. M. Schaffer et al., "Major histocompatibility complex class III genes and susceptibility to immunoglobulin A deficiency and common variable immunodeficiency," Journal of Clinical Investigation, vol. 89, no. 6, pp. 1914-1922, 1992.

[109] O. Olerup, C. I. E. Smith, J. Bjorkander, and L. Hammarstrom, "Shared HLA class II-associated genetic susceptibility and resistance, related to the HLA-DQB1 gene, in IgA deficiency and common variable immunodeficiency," Proceedings of the National Academy of Sciences of the United States of America, vol. 89, no. 22, pp. 10653-10657, 1992.

[110] I. Vořechovský, M. Cullen, M. Carrington, L. Hammarström, and A. D. B. Webster, "Fine mapping of IGAD1 in IgA deficiency and common variable immunodeficiency: identification and characterization of haplotypes shared by affected members of 101 multiple-case families," Journal of Immunology, vol. 164, no. 8, pp. 4408-4416, 2000.

[111] J. Kralovicova, L. Hammarström, A. Plebani, A. D. B. Webster, and I. Vorechovsky, "Fine-scale mapping at IGAD1 and genome-wide genetic linkage analysis implicate HLA-DQ/DR as a major susceptibility locus in selective IgA deficiency and common variable immunodeficiency," Journal of Immunology, vol. 170, no. 5, pp. 2765-2775, 2003.

[112] H. Sekine, R. C. Ferreira, Q. Pan-Hammarström et al., "Role for Msh5 in the regulation of Ig class switch recombination," Proceedings of the National Academy of Sciences of the United States of America, vol. 104, no. 17, pp. 7193-7198, 2007.

[113] B. D. Harfe and S. Jinks-Robertson, "DNA mismatch repair and genetic instability," Annual Review of Genetics, vol. 34, pp. 359-399, 2000.

[114] J. A. Surtees, J. L. Argueso, and E. Alani, "Mismatch repair proteins: key regulators of genetic recombination," Cytogenetic and Genome Research, vol. 107, no. 3-4, pp. 146-159, 2004.

[115] J. E. J. Guikema, C. E. Schrader, N. G. J. Leus et al., "Reassessment of the role of Mut $S$ homolog 5 in Ig class switch recombination shows lack of involvement in cis- and transswitching," Journal of Immunology, vol. 181, no. 12, pp. 8450-8459, 2008.

[116] S. M. Offer, Q. Pan-Hammarström, L. Hammarström, and R. S. Harris, "Unique DNA repair gene variations and potential associations with the primary antibody deficiency syndromes igAD and CVID," PLoS ONE, vol. 5, no. 8, Article ID e12260, 2010. 
[117] N. D. Pozo, L. M. Medrano, M. C. Cénit et al., "MSH5 is not a genetic predisposing factor for immunoglobulin A deficiency but marks the HLA-DRB1*0102 subgroup carrying susceptibility," Human Immunology, vol. 71, pp. 861-864, 2010.

[118] D. L. Wassom and E. A. B. Kelly, "The role of the major histocompatibility complex in resistance to parasite infections," Critical Reviews in Immunology, vol. 10, no. 1, pp. 31-52, 1990.

[119] M. W. Kennedy, "Genetic control of the immune repertoire in nematode infections," Parasitology Today, vol. 5, no. 10, pp. 316-324, 1989.

[120] T. Dainichi, Y. Maekawa, K. Ishii et al., "Nippocystatin, a cysteine protease inhibitor from Nippostrongylus brasiliensis, inhibits antigen processing and modulates antigenspecific immune response," Infection and Immunity, vol. 69, no. 12, pp. 7380-7386, 2001.

[121] J. S. Knight, D. B. Baird, W. R. Hein, and A. Pernthaner, "The gastrointestinal nématode Tricostrongylus colubriformis down-regulates immune gene expression in migratory cells in afferent lymph," BMC Immunology, vol. 11, article 51, 2010.

[122] D. L. Wassom, C. J. Krco, and C. S. David, "I-E expression and susceptibility to parasite infection," Immunology Today, vol. 8, no. 2, pp. 39-43, 1987.

[123] O. M. Keane, A. Zadissa, T. Wilson et al., "Gene expression profiling of Naïve sheep genetically resistant and susceptible to gastrointestinal nematodes," BMC Genomics, vol. 7, article 42, 2006.

[124] N. Charbonnel and J. Pemberton, "A long-term genetic survey of an ungulate population reveals balancing selection acting on MHC through spatial and temporal fluctuations in selection," Heredity, vol. 95, no. 5, pp. 377-388, 2005.

[125] S. Paterson, "Evidence for balancing selection at the major histocompatibility complex in a free-living ruminant," Journal of Heredity, vol. 89, no. 4, pp. 289-294, 1998.

[126] D. Beraldi, A. F. McRae, J. Gratten et al., "Quantitative trait loci (QTL) mapping of resistance to strongyles and coccidia in the free-living Soay sheep (Ovis aries)," International Journal for Parasitology, vol. 37, no. 1, pp. 121-129, 2007. 

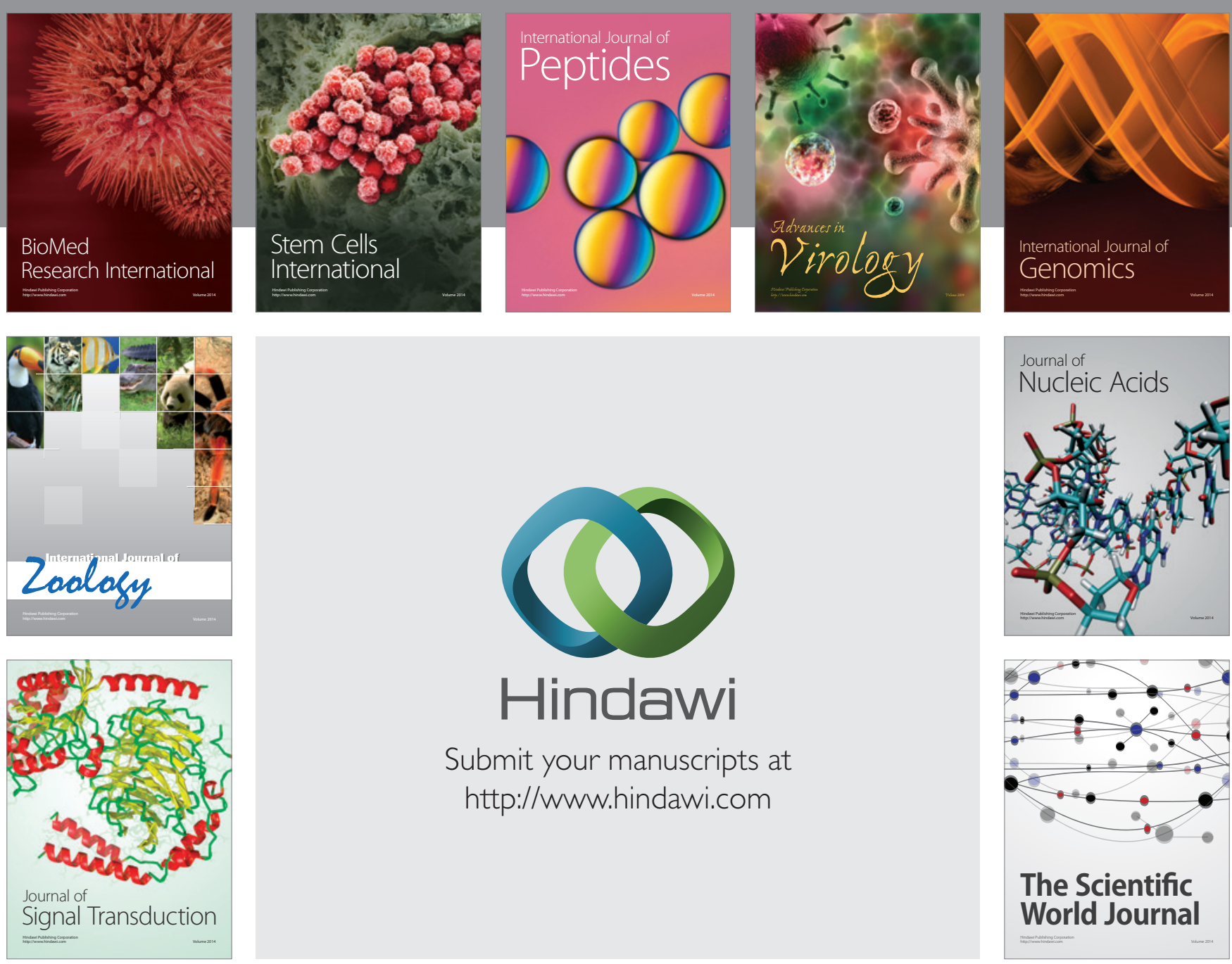

Submit your manuscripts at

http://www.hindawi.com
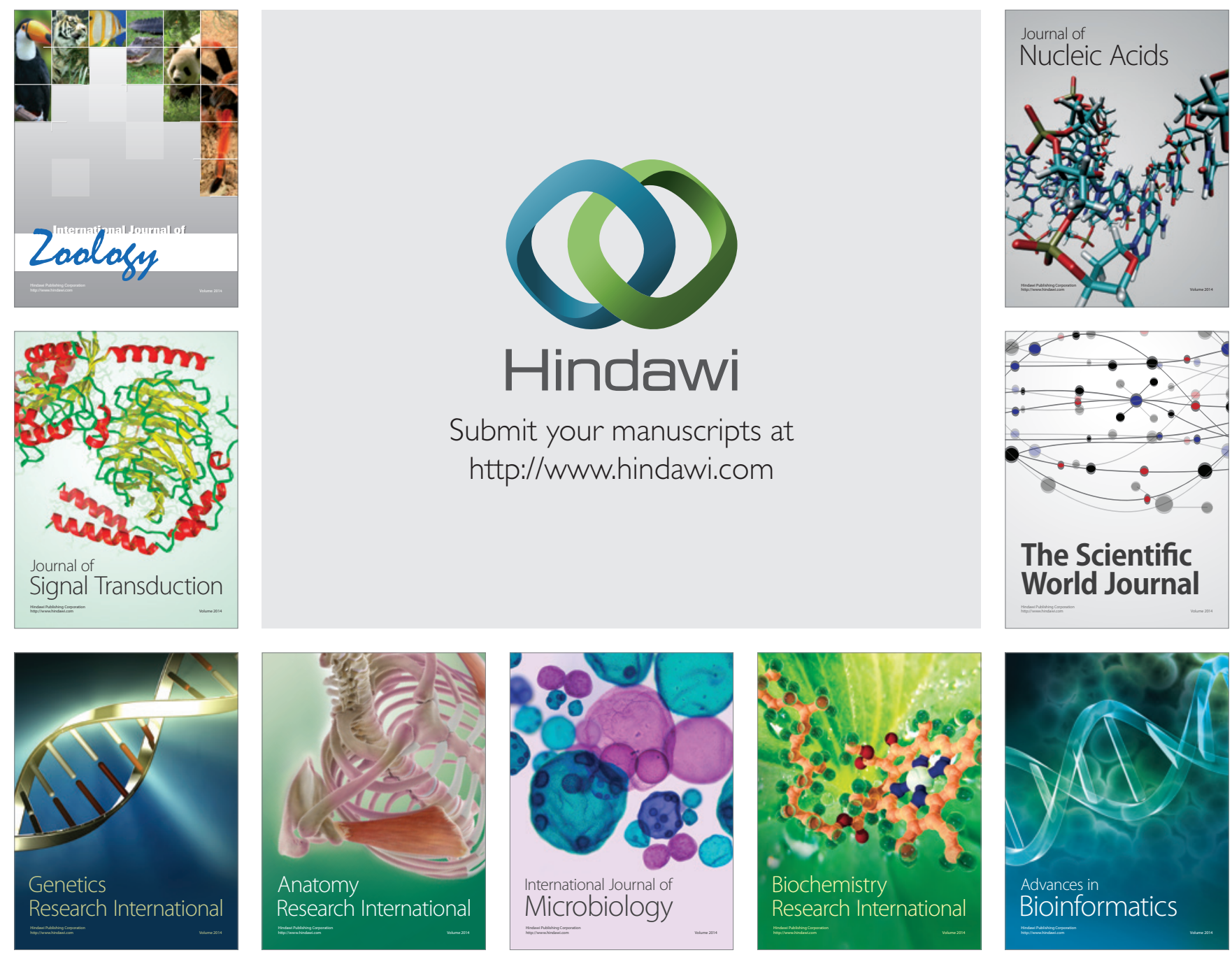

The Scientific World Journal
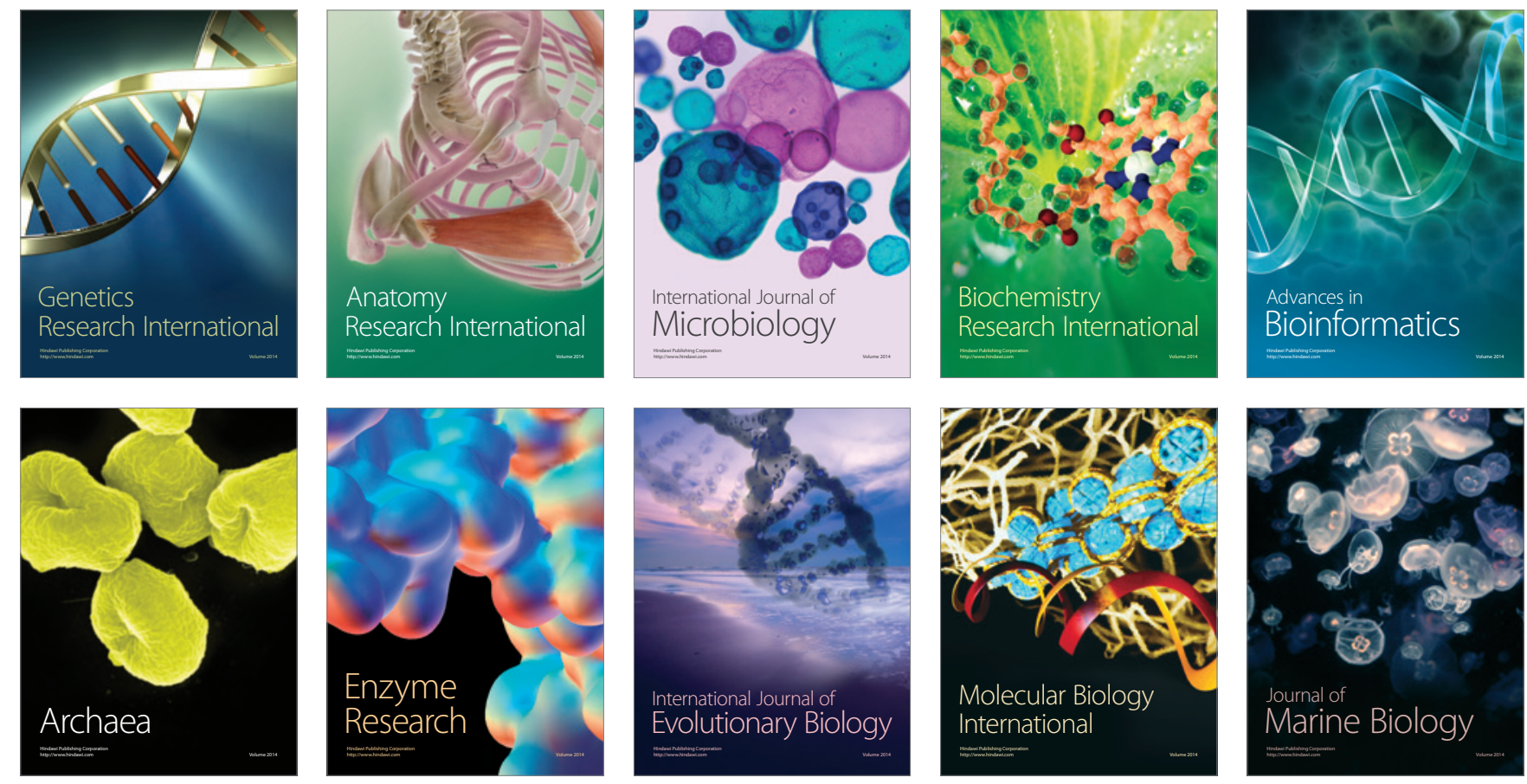